\title{
EDITORIAL
}

\section{ERS position paper: work-related respiratory diseases in the EU}

\author{
T. Sigsgaard*, D. Nowak\#, I. Annesi-Maesano`, B. Nemery ${ }^{+}, K_{\text {. Torén }}^{\S}$, G. Viegi ${ }^{\dagger}$, K. Radon**, S. Burge ${ }^{\# \#, ~}$ \\ D. Heederik" and the ERS EOH group 6.2
}

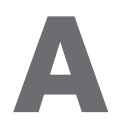
ccording to a 2000 estimate based on workforce data and the CAREX (Carcinogen Exposure) database [1] there were 386,000 deaths worldwide due to noncancer respiratory diseases (asthma: 38,000; chronic obstructive pulmonary disease (COPD): 318,000; pneumoconioses: 30,000) and nearly 6.6 million disability-adjusted life years (DALYs) (asthma: 1,621,000; COPD: 3,733,000; pneumoconioses: $1,288,000)$ attributable to occupational exposure to airborne particulates. The same figures for Europe were 52,700 deaths (asthma: 6,200; COPD: 39,300; pneumoconioses: 7,200) and 868,000 DALYs (asthma: 139,000; COPD: 468,000; pneumoconioses: 261,000). Respiratory diseases rank as the third most prevalent occupational disease category (after ergonomic and stress-related diseases) according to a survey of occupational diseases in the European Union (EU). The prevalence of respiratory diseases was 296 per 100,000 population, with the highest proportion found in the mining industry. This amounts to almost 600,000 persons in the former 15 member states. Many of these diseases, though induced while working, are chronic, thus explaining the highest prevalence among older workers (0.5\% aged 55-64 yrs).

Traditional high-risk occupations, such as mining, farming, manufacturing and service work (e.g. hairdressers), are among the professions with a high prevalence of occupational lung diseases. However, high rates of occupational lung disease are also seen in newer professions, such as public administration, education [2] and occupational cleaning; the latter could be a reflection of problems related to new cleaning procedures, as found by the European Community Respiratory Health Survey (ECRHS) [3], or to problems with indoor air in public spaces.

The pneumoconioses induced by exposure to mineral and other dusts at high concentrations were the dominating occupational lung diseases in the early industrialisation era. Their prevalence has been decreasing during the past decades.

*Institute of Environmental Medicine, University of Aarhus, Aarhus, Denmark. ${ }^{*}$ Institute for Occupational and Environmental Medicine, Ludwig-Maximilians University, and ${ }^{* *}$ Institute for Occupational and Environmental Medicine, University of Munich, Munich, Germany. "EPAR, INSERM, Paris, France. ${ }^{+}$Pneumology, Catholic University Leuven, Leuven, Belgium. ${ }^{5}$ Dept of Occupational Medicine, Section of Allergology, Sahlgrenska University Hospital, Institute of Internal Medicine, Gothenburg, Sweden. ${ }^{f}$ Institute of Clinical Physiology, National Research Council, Pisa, Italy. ${ }^{\# \#}$ Occupational Lung Disease Unit, Birmingham Heartlands Hospital, Birmingham, UK. "IRAS EEPI Division, University of Utrecht, Utrecht, The Netherlands.

CORRESPONDENCE: T. Sigsgaard, Inst Environmental Medicine, University of Aarhus, Bartholin Allé 2, Aarhus, Denmark. E-mail: Sigsgaard@dadlnet.dk
At the same time the obstructive lung diseases have gained increased importance, first because these diseases are widespread in the population, hence even small occupational contributions are important for society, and secondly because smoking has become less common during the same period, thereby revealing the "true" burden of occupational exposures, especially on COPD.

Although mining and quarrying are decreasing in industrially advanced countries, new technologies have introduced known exposures to new groups of workers. One example of this is the recurrence of silicotic lesions in construction workers, shown to coincide with the new technique of hand-held high-speed tools now in common use on construction sites. These new tools are a challenge to us all, since they introduce a potential dangerous exposure to groups of workers unaware of the associated risk [4].

For malignant diseases we are facing an epidemic of malignant mesothelioma caused by the intensive use of asbestos up to the late 1980s. The number of annual cases is predicted to increase steadily until 2020 in the old member states, and perhaps even later in the new member states [5].

A comparative study on the impact of type of labour on mortality in 11 EU countries has shown that middle-aged males in manual work run a two-fold higher risk of dying from respiratory diseases, compared to non-manual workers (mortality rate ratio from 1.63 to 2.63). Although these data are based on mortality occurring up to $20 \mathrm{yrs}$ ago, reflecting exposures that occurred even earlier, the trends are still important for public health reasons [6]. A Danish study showed a negative association between social status in males and mortality from respiratory diseases, which persisted after correction for smoking habits [7]. It is a challenge to understand the underlying reasons for the difference related to social class. However, social class and smoking are linked to other factors, such as education, social network and healthier lifestyle, i.e. the ability to adapt to the changing challenges in society. These factors all combine and are among the primary reasons, but an important fraction of the social inequality is probably related to working conditions which, by themselves, increase the risk of chronic lung diseases like COPD and the classic pneumoconioses occurring predominantly in manufacturing industries.

In this paper, a brief overview is given of the epidemiology of the respiratory diseases involved, with their old and new risk 
factors. The information for the different respiratory diseases comes from several sources. For a specific respiratory cancer, such as mesothelioma, registered causes of death from national mortality statistics can be used. For some diseases, such as occupational asthma, occupational disease registries exist, either as monitoring instruments or for insurance purposes. For multi-causal diseases, such as COPD and lung cancer, information comes from dedicated analytical epidemiological studies.

\section{DISEASES \\ COPD}

COPD is responsible for an increasing morbidity and mortality worldwide $[8,9]$. The population attributable risk (PAR) from occupational exposure is now estimated at $15-20 \%$ [10]. This is far more than has been anticipated from earlier studies, when smoking was thought to account for all or most of the disease. A recent study of construction workers from Sweden showed that the attributable fraction of dusty environments was even higher. For smokers, $10 \%$ of the COPD was attributed to occupational exposure, and among never-smokers $50 \%$ of the COPD was attributed to occupation [11]. An analysis of the occupational exposures on COPD in the ECRHS showed that high exposure to dust and fumes, as defined by a job exposure matrix, increased the risks from smoking by an OR of $1.60(95 \%$ CI 1.0-2.5) for chronic bronchitis. The risk was also present in ex-smokers, but not significantly so [12]. Examples of occupational risk factors for COPD are dust, e.g. from coal, silica and organic material, oil mists and welding fumes.

\section{Occupational asthma and work-aggravated asthma}

The ECRHS has shown a great variation in the prevalence rates of self-reported asthma in different centres across Europe, between countries as well as within countries [13]. The increasing prevalence of asthma in childhood has resulted in an increasing number of asthmatics entering the workforce, producing new challenges for industries that traditionally excluded asthmatics from employment. The new cohorts of young people show a prevalence of allergy of $20 \%$ and of asthma of $8 \%$. This will increase the number of people suffering work-aggravated asthma and be an increasing challenge for the years to come.

Asthma is a disease occurring in people exposed to an environment towards which they are susceptible. Twin studies have shown that the environmental contribution to asthma is $\sim 30 \%$ [14]. The burden of the environment is probably even higher for adult-onset asthma. Atopy, defined as skin-prick test reactions towards common inhalant allergens, is found to be a risk factor in various occupations with exposure to high molecular weight allergens of biological origin. For sensitising agents causing non-immunoglobulin (Ig)E-mediated asthma (mostly synthetic chemicals of low molecular weight), atopy is not a risk factor. Although no uniform dose-response relationship exists for allergens and other sensitisers, most well performed studies of workers show a positive association between the risk of asthma and increasing intensity of exposure [15].

More than 400 different chemical and biological agents have been shown to induce occupational asthma; for references on causative agents please consult the Occupational Asthma website in English [16] or Asmapro, a web server providing information on occupational asthma in French and English [17].

The vast majority of these have been found on clinical grounds and confirmed in experimental settings. It is, therefore, important to consider, in each country or region, centralised units with expertise in diagnosing occupational asthma, including the capability of performing specific occupational type bronchial provocation tests, which is considered the gold standard for establishing the diagnosis and confirming new causes. These facilities are particularly needed when new cases of non-IgE-mediated asthma are suspected. One recent example of such a finding in a multicentre study is the increased risk of asthma in cleaners, found in the ECHRS study [3].

\section{HIGH-RISK OCCUPATIONS}

In France, the six highest risk occupations for occupational asthma were car painters (33 per 100,000 per year), hairdressers (31 per 100,000 per year), woodworkers (22 per 100,000 per year), cleaners (six per 100,000 per year) and healthcare workers (four per 100,000 per year) (from the Observatoire National des Asthmes Professionnels, 1996-1999) [18]. The most often implicated agents were isocyanates, latex, alkaline persulphates and aldehydes.

In the UK, occupational asthma is the most commonly reported occupational lung disease in the Surveillance of Work-related and Occupational Respiratory Disease (SWORD) [19]. The rate of short-latency respiratory diseases was highest in the mining industry (56 per 100,000 per year), mostly due to a high rate of inhalation accidents, followed by the chemical industry (33 per 100,000 per year), non-metallic mineral products (30 per 100,000 per year), motor vehicle manufacture (27 per 100,000 per year), food manufacture (23 per 100,000 per year) and metal manufacture (22 per 100,000 per year).

For the respiratory diseases with a long latency, the British SWORD system reported the rate of mesothelioma to be highest among construction workers (18 per 100,000 per year), followed by woodworkers (15 per 100,000 per year), electrical workers (10 per 100,000 per year), coal gas workers (seven per 100,000 per year) and engineering (seven per 100,000 per year). For pneumoconioses, the five highest rates were in construction workers (29 per 100,000 per year), followed by miners and quarrymen (27 per 100,000 per year), woodworkers (19 per 100,000 per year), coal gas workers (15 per 100,000 per year), and electrical workers (12 per 100,000 per year) [20].

Data on COPD related to occupation are scarce, since the only recognised risk factor for COPD, until very recent years, has been smoking.

\section{Historical risks}

Mesothelioma shows an increasing trend in the European community, and it is estimated that the "epidemic" of mesothelioma is going to peak around 2020 in Europe. At the same time, figures from the UK show that there is a change in the risk groups from the traditionally exposed occupations towards secondary occupations, and females are now increasingly developing mesotheliomas [21]

Pneumoconiosis prevalence has remained static over the years, but is forecast to decrease in birth cohorts born after 1950; 
however, there will be a substantial proportion of the population with pneumoconioses for the decades to come.

\section{New risks}

There is a constant change in industrial processes and materials, creating new exposures to the workforce, and sometimes these new environments create unforeseen risks to the workers exposed. Thus, in the 1990s a very severe form of interstitial lung disease, called Ardystil syndrome, affected Spanish and Algerian textile workers who had been engaged in spraying paints that were reputedly non-toxic [22, 23]. Another novel pulmonary disease, flock worker's lung, has recently been described in workers exposed to synthetic micro fibres (flock) of nylon [24], polyethylene [25] or polypropylene [26], although such polymeric materials are generally considered to be devoid of significant toxicity. Recently, serious airways disease affected workers from plants producing microwave popcorn "popcorn worker's lung" [27, 28], probably as a result of their inhalatory exposure to artificial flavouring agents that are "generally recognised as safe" [28].

These examples, together with the constant increase in the list of compounds causing occupational asthma, call for a constant surveillance of the workforce, in order to identify new risks and the resurgence of old risks in the workforce. Lately, it has been shown in a range of studies from Europe that construction workers run a risk of silicosis due to high amounts of dust containing quartz liberated from construction materials during cutting and drilling with high-speed tools. Because of the dissemination and power of these tools, there is an increasing bystander problem associated with their use [4]. In recent analyses of the ECRHS, a new or not previously recognised risk relating to cleaning has been shown, emphasising that conventional workplace studies might not find risks associated with work when these risks are disseminated across industries, and not concentrated in single factories, which historically have been the most frequent setting for occupational surveys [3].

A new type of compounds with a potential adverse impact on respiratory health consists of manufactured (or engineered) nanomaterials. So far, nanomaterials are a "cause waiting for a disease". However, knowledge from experimental studies with nanomaterials, and experience with environmental nanoparticles (known as ultrafine particles) and with persistent materials, such as asbestos fibres, must lead us to exert extreme caution with the emergence of a vast range of nanomaterials, some of which are, or will be, composed of unusual chemical agents. Moreover, it must be realised that the very reason why such great technological efforts are made to develop and produce materials at the nanoscale is to obtain properties that are not present at larger sizes. So, by definition, the biological properties of nanoparticles cannot be inferred simply from our knowledge of their classical chemistry. Thus, although inhalation studies with some nanosized titanium dioxide has been found to be non-toxic [29], this cannot be generalised to all nanoparticles, and exposure to nanoparticles should be limited to the minimum, since it is not clear what drives the health effect of particles of this size. In view of the increasing technological trend to develop nanomaterials, this notion must be kept in mind whenever materials, even those with a relatively good safety record (e.g. carbon), are developed for novel applications. This applies particularly for materials with high bio-persistence, such as carbon nanotubes. Thus, it is noteworthy that carbon nanotubes introduced into the abdominal cavity of mice show asbestos-like pathogenicity [30] and may induce mesothelioma in mice [31].

According to a review by the English Health and Safety Executive, examples of industries where exposures to engineered nanoparticles are likely to occur are: the nanotechnology sector, primarily research and development, including university departments and spin-out companies; existing ultrafine manufacture; manufacturing processes, including carbon black and fumed silica; and powder handling processes, including paints, pigments and cement manufacture [32].

\section{The economic burden and social consequences}

A working group of the American Thoracic Society has calculated the PAR for work-related asthma and COPD to be $\sim 15 \%$ [33]. Since these diseases are common in the population, the economic burden related to a PAR of this magnitude constitutes a serious challenge to public health. An economical analysis based on these PARs showed that the cost of occupationally caused asthma and COPD would be approximately US\$7 billion annually, not taking into account pneumoconioses and malignant lung diseases. If these figures are translated directly to the European area this would amount to an annual cost of $€ 5$ billion in the old EU, and approximately $€ 6.4$ billion in the greater EU including the new member states. These predictions do not take into account the loss of productivity and health related to increased morbidity in the increasing proportion of the European population with pre-existing asthma and allergies, when they enter the labour market. At the same time, the workforce is also getting older and a survey of European workers have found an increasing prevalence of "breathing difficulties" in the group of workers aged $>55$ yrs compared to the younger workforce [34]. Several European states are in the process of increasing the pension age and there is a need to focus on the susceptibility of the older workforce when exposed to the occupational exposures in the modern industrial setting.

For the individual experiencing occupational asthma, one study has shown that affected individuals lose much more income than asthmatics with another aetiology. This is probably a reflection of the grave consequences it has on the workability of persons whose disease is caused by exposures that they have been trained to work with [35]. In this respect, it is worthwhile underlining the effectiveness of primary and secondary prevention in reduction of costs concerning occupational asthma and COPD [36].

\section{REGULATORY ASPECTS AND DEVELOPMENTS}

Exposure to toxic agents is regulated in different ways. An important tool is the EU REACH regulatory process for existing and new chemicals. The aim of REACH is to regulate chemical products, and it will prescribe so-called exposure scenarios and certain ways in which chemical agents have to be processed, in order to reduce the exposure of workers in processing industries and of consumers. However, major categories of respiratory toxic agents with large populations at risk, such as minerals and enzymes used in food production, will not be regulated by REACH. In addition, agents that have no particular owner like, for instance, combustion products, 
such as diesel particulates or micro-organisms producing (endo) toxins on agricultural products, will not be regulated by REACH.

An important alternative tool for preventing occupational respiratory diseases consists of setting exposure standards. Standards will tie exposure in the work environment to an upper legal limit. The mechanisms for deriving occupational exposure standards is very similar to the process that exists for environmental exposure standards, such as the one for fine particulate matter in the air. Usually a complete literature review is produced and a risk assessment process should lead to a proposal for a health-based occupational exposure limit. The major producers of occupational standards have traditionally been the UK (Watch Committee), the Netherlands (Dutch Expert Committee of the Dutch Health Council), Germany (The Senate Commission for the Investigation of Health Hazards of Chemical Compounds in the Work Area) and the Scandinavian Countries (Nordic Expert Group). In several of these countries, standard setting procedures are under pressure from deregulating governments. It is expected that in the EU, the Scientific Committee on Occupational Exposure Limits (SCOEL) will become the major standard setting body in the near future. The aim of the SCOEL is to provide scientific advice to the European Commission to underpin regulatory proposals on exposure limits for chemicals in the workplace within the framework of the chemical agents Directive 98/24/EC and the carcinogens at work Directive 90/394/EEC as amended. Its mandate is to examine available information on toxicological and other relevant properties of chemical agents, evaluate the relationship between the health effects of the agents and the level of occupational exposure and, where possible, recommend values for occupational exposure limits, thereby protecting workers from chemical risks. However, this committee has a low budget. Hence, production of standards has so far been limited and the process is slow.

\section{CONCLUSION}

Respiratory diseases rank third among occupational diseases in the European population. Furthermore, these diseases impose serious social and life quality problems in the affected people. Among the diseases with long latency time, the PAR for COPD from occupational exposure is now estimated at 15$20 \%$. Among the diseases with short latency time, an increasing problem is foreseen for work-aggravated asthma, since there is an increasing prevalence of asthma in the cohorts about to enter the workforce in the European countries.

Using US data on the economical impact of occupational respiratory diseases, we estimate that the burden on the EU member states amounts to $€ 6.4$ billion annually including the costs in the new member states.

Therefore, there is a need for the EU to fight these diseases, and to coordinate European and national strategies in this respect. Only then will we be able to increase the health of the workforce, and bring down the costs imposed on the health system. It is imperative that the knowledge of the respiratory burden is disseminated to employers, who bear the responsibility for a safe and sound work environment according to current EU legislation [37]. In 2006 the EU banned the handling of asbestos in any form and a campaign was launched on the safety issues of asbestos. In 2007 a new campaign was launched to bring down the accidents and illnesses at work by $25 \%$ by 2012 . We need specific action to translate these general aims into action for some of the major categories of occupational respiratory diseases. There is a role for the European Respiratory Society (ERS) in defining these goals and ascertaining that these goals will be met in order to protect workers' respiratory health and well-being.

Last but not least many healthcare professions have limited knowledge of occupational lung diseases, and the exposures which cause them. This results in missed diagnoses and poor advice about continuing or leaving work, and subsequent loss of productivity. This lack of knowledge, and lack of teaching resources in many medical schools, has been recognised by the EU, which has supported the NETWORM (Net-based Training for Work-related Medicine) project. This project provides internet-based interactive cases that can be adapted to local/ national political and legal systems. The ERS will strive to have occupational lung diseases included in the core curriculum of general practitioners, as well as lung physicians, throughout the EU and beyond, in order to enable health professionals at all levels to recognise occupational lung diseases, whenever they are confronted with such cases.

\section{STATEMENT OF INTEREST}

Statements of interest for B. Nemery and S. Burge can be found at www.erj.ersjournals.com/misc/statements.dtl

\section{REFERENCES}

1 Driscoll T, Nelson DI, Steenland K, et al. The global burden of nonmalignant respiratory disease due to occupational airborne exposures. Am J Ind Med 2005; 48: 432-445.

2 Jaakkola JJ, Piipari R, Jaakkola MS. Occupation and asthma: a population-based incident case-control study. Am J Epidemiol 2003; 158: 981-987.

3 Zock JP. World at work: cleaners. Occup Environ Med 2005; 62: 581-584.

4 Tjoe NE, Heederik D. Risk assessment of silicosis and lung cancer among construction workers exposed to respirable quartz. Scand $J$ Work Environ Health 2005; 31: Suppl. 2, 49-56.

5 Hodgson JT, McElvenny DM, Darnton AJ, et al. The expected burden of mesothelioma mortality in Great Britain from 2002 to 2050. Br J Cancer 2005; 92: 587-593.

6 Kunst AE, Groenhof F, Mackenbach JP, et al. Occupational class and cause specific mortality in middle aged men in 11 European countries: comparison of population based studies. EU Working Group on Socioeconomic Inequalities in Health. BMJ 1998; 316: 1636-1642.

7 Prescott E, Godtfredsen N, Vestbo J, et al. Social position and mortality from respiratory diseases in males and females. Eur Respir J 2003; 21: 821-826.

8 Anto JM, Vermeire P, Vestbo J, et al. Epidemiology of chronic obstructive pulmonary disease. Eur Respir J 2001; 17: 982-994.

9 Murray CJ, Lopez AD. Alternative projections of mortality and disability by cause 1990-2020: Global Burden of Disease Study. Lancet 1997; 349: 1498-1504.

10 Viegi G, Di Pede C. Chronic obstructive lung diseases and occupational exposure. Curr Opin Allergy Clin Immunol 2002; 2: 115-121.

11 Bergdahl IA, Toren K, Eriksson K, et al. Increased mortality in COPD among construction workers exposed to inorganic dust. Eur Respir J 2004; 23: 402-406. 
12 Zock JP, Sunyer J, Kogevinas M, et al. Occupation, chronic bronchitis, and lung function in young adults. An international study. Am J Respir Crit Care Med 2001; 163: 1572-1577.

13 Variations in the prevalence of respiratory symptoms, selfreported asthma attacks, and use of asthma medication in the European Community Respiratory Health Survey (ECRHS). Eur Respir J 1996; 9: 687-695.

14 Skadhauge LR, Christensen $\mathrm{K}$, Kyvik KO, et al. Genetic and environmental influence on asthma: a population-based study of 11,688 Danish twin pairs. Eur Respir J 1999; 13: 8-14.

15 Newman Taylor AJ, Cullinan P, Burge PS, et al. BOHRF guidelines for occupational asthma. Thorax 2005; 60: 364-366.

16 Oasys. Occupational Asthma Causative Agents/Sensitizers. www. occupationalasthma.com/causative_agents.aspx Date last updated: October 29, 2009. Date last accessed: December 1, 2009.

17 Asmapro: A Web Server for Occupational Asthma. www. remcomp.fr/asmanet/asmapro/asmawork.htm Date last updated: October 27, 2006. Date last accessed: December 1, 2009.

18 Ameille J, Pauli G, Calastreng-Crinquand A, et al. Reported incidence of occupational asthma in France, 1996-99: the ONAP programme. Occup Environ Med 2003; 60: 136-141.

19 Meyer JD, Holt DL, Cherry NM, et al. SWORD '98: surveillance of work-related and occupational respiratory disease in the UK. Occup Med (Lond) 1999; 49: 485-489.

20 Meyer JD, Holt DL, Chen Y, et al. SWORD '99: surveillance of work-related and occupational respiratory disease in the UK. Occup Med (Lond) 2001; 51: 204-208.

21 McElvenny DM, Darnton AJ, Price MJ, et al. Mesothelioma mortality in Great Britain from 1968 to 2001. Occup Med (Lond) 2005; 55: 79-87.

22 Moya C, Anto JM, Taylor AJ. Outbreak of organising pneumonia in textile printing sprayers. Collaborative Group for the Study of Toxicity in Textile Aerographic Factories. Lancet 1994; 344: 498-502.

23 Ould KF, Mohammed-Brahim B, Fyad A, et al. Outbreak of pulmonary disease in textile dye sprayers in Algeria. Lancet 1994; 344: 962-963.

24 Kern DG, Crausman RS, Durand KT, et al. Flock worker's lung: chronic interstitial lung disease in the nylon flocking industry. Ann Intern Med 1998; 129: 261-272.
25 Barroso E, Ibanez MD, Aranda FI, et al. Polyethylene flockassociated interstitial lung disease in a Spanish female. Eur Respir J 2002; 20: 1610-1612.

26 Atis S, Tutluoglu B, Levent E, et al. The respiratory effects of occupational polypropylene flock exposure. Eur Respir J 2005; 25 110-117.

27 Kreiss K, Gomaa A, Kullman G, et al. Clinical bronchiolitis obliterans in workers at a microwave-popcorn plant. $N$ Engl J Med 2002; 347: 330-338.

28 Akpinar-Elci M, Travis WD, Lynch DA, et al. Bronchiolitis obliterans syndrome in popcorn production plant workers. Eur Respir J 2004; 24: 298-302.

29 Grassain VH, O'Shaughnessy PT, Adamcakova-Dodd A, et al. Inhalation exposure study of titanium dioxide nanoparticles with a primary particle size of 2 to $5 \mathrm{~nm}$. Environ Health Perspect 2007; 115: 397-402.

30 Poland CA, Duffin R, Kinloch I, et al. Carbon nanotubes introduced into the abdominal cavity of mice show asbestos-like pathogenicity in a pilot study. Nat Nanotechnol 2008; 3: 423-428.

31 Takagi A, Hirose A, Nishimura T, et al. Induction of mesothelioma in p53+/- mouse by intraperitoneal application of multi-wall carbon nanotube. J Toxicol Sci 2008; 33: 105-116.

32 Aitken R, Creely K, Tran C. Nanoparticles: An Occupational Hygiene Review. Norwich, UK Institute of Occupational Medicine, 2004.

33 ATS. American Thoracic Society statement: occupational contribution to the burden of airway disease. Am J Respir Crit Care Med 2003; 167: 787-798.

34 Villosio C, Di Pierro D, Giordanengo A, et al. Working Conditions of an Ageing Workforce. Luxemburg, European Foundation for the Improvement of Living and Working Conditions, 2008.

35 Vandenplas O, Toren K, Blanc PD. Health and socioeconomic impact of work-related asthma. Eur Respir J 2003; 22: 689-697.

36 Moscato G, Rampulla C. Costs of occupational asthma and of occupational chronic obstructive pulmonary disease. Curr Opin Allergy Clin Immunol 2003; 3: 109-114.

37 EU. EUROSTAT. Work-related illness and accidents should be cut by a quarter across the EU. http://osha.europa.eu/en/press/ press-releases/reducing-work-related-accidents / Date last updated: June 13, 2008. Date last accessed: December 1, 2009. 